\title{
Ergenlerde Akademik Başarıya İlişkin Bilişsel Çarpıtmalar ile Algılanan Anne Baba Tutumu Arasındaki İlişki
}

DOI: $10.26466 /$ opus.791965

*

İdris Kaya *

* Dr. Öğr. Üyesi, Gaziantep Üniversitesi

Öz

ORCID: $0000-0001-9562-3347$

Bu çalışmada; ergenlerin algıladığı anne baba tutumları ile başarıya ilişkin bilişsel çarpıtmaları arasındaki ilişsilerin incelenmesi amaçlanmıştır. Çalışmanın verileri biri Anadolu biri meslek lisesi olmak üzere iki farklı okul türünden toplanmıştır. Çalışma grubu 15-19 yaş aralığında ( $\overline{\mathrm{X}}=16,30 ;$ ss= .95) ve 79'u kadın $(\% 35,9)$ 141'i erkek $(\% 64,1)$ olmak üzere toplam 220 kişiden oluşturmaktadır. Araştırmanın verileri anne baba tutum ölçeği (ABTÖ) ve akademik başarıya ilişkin bilişsel çarpıtmalar ölçeği ( АВїВÇÖ) ile toplanmıştır. Bulgular; akademik başarıya ilişkin bilişsel çarpıtmaların cinsiyet ve okul türüne göre anlamlı bir farklıllk göstermediğini ortaya koymuştur. Bunun yanında anne baba tutumlarından kabullilgi ve psikolojik özerklik cinsiyete göre farklılı göstermez iken denetleme kadınlar lehine anlaml farklılık göstermektedir. Algllanan anne baba tutumlarından psikolojik özerklik Anadolu lisesi lehine anlaml farklılık gösterirken, kabullilgi ve denetleme okul türüne göre anlamlı bir farklılık göstermemektedir. Değişkenler arasındaki ilişkiler incelendiğinde, ABİBÇÖ ile psikolojik özerklik arasında negatif yönlü orta düzeyde anlaml bir ilişki olduğu, ABIBBÇÖ ile kabullilgi ve denetleme arasında anlamlı bir ilişki olmadığı belirlenmiştir. Değişkenler arasında yapılan regresyon analizinde ise anne baba tutumlarından psikolojik özerkliğin ABİBÇÖ puanında gözlenen varyansın \%13'ünü açıkladığı tespit edilmiştir.

Anahtar Kelimeler: Bilişsel çarpıtma, akademik başarı, anne baba tutumu 


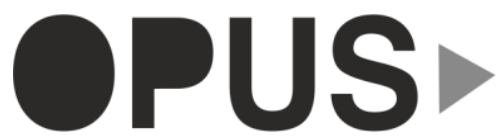

Uluslararası Toplum Araştırmaları Dergisi International Journal of Society Researches
E-ISSN : 2528-9535

YIl Year: 10

Cilt Volume: 16

Sayı Issue :Eğitim ve Toplum Özel Sayısı

Aralık December 2020

Makalenin Geliș Tarihi Received Date: 08/09/2020

Makalenin Kabul Tarihi Accepted Date: 28/12/2020

\title{
The Relationship Between Cognitive Distortions Related to Academic Achievement and Perceived Parental Attitude at Adolescents
}

\begin{abstract}
The purpose of this study was to investigate the relationships between the perceived parents' attitude and the cognitive distortions related to academic achievement at adolescent. The working group of study is consists of a total of 220 high school students between the ages of $15-19(\overline{\mathbf{X}}=16.30 ;$ ss $=.95)$ and 79 of them are female $(35.9 \%)$ and 141 of them are male $(64.1 \%)$. The data were collected by the parental attitude scale and the cognitive distortions scale related to academic achievement (CDS-AA). The findings of the study show that cognitive distortions related to academic achievement do not differ significantly by gender and school type. Acceptance / involvement and psychological autonomy from parents' not differ by gender, whereas the strictness/supervision differs significantly in favour of women. However, while acceptancelinvolvement and strictness/supervision did not differ according to the school type, psychological autonomy showed a significant difference in favour of academic high school. Lastly, it was determined that there was a moderate negative relationship between CDS-AA and psychological autonomy, and there was no significant relationship between CDS-AA and acceptance/involvement and strictness/supervision. The regression analysis conducted between the variables, shown that the perceived psychological autonomy explained CDS-AA's $13 \%$ of the variance.
\end{abstract}

Keywords: Cognitive distortions, academic achievement, parental attitude 


\section{Giriş}

Bilişsel davranışçı terapinin (BDT) çocuk ve ergen ruh sağlı̆̆ının korunmasinda (Rohde, Brière ve Stice, 2018) ve tedavi edilmesinde etkili bir ruh sağlı̆̆1 modeli olduğu (Kazantzis ve diğerleri, 2018; McGuire ve diğerleri, 2015; Seligman ve Ollendick, 2011) ve bu modeli merkeze alarak yapılan müdahalelerin etkisinin yıllarca devam ettiği (Barrett, Duffy, Dadds ve Rapee, 2001) çeşitli çalışmalar ile ortaya konmuştur. Bu yaklaşım düşünce ve inançların, ruh sağlı̆̆ının temel belirleyicilerinden olduğunu ve kişinin düşünme sistematiğinde bazen ruh sağlığını olumsuz etkileyecek çarpıtılmış düşüncelerin olabileceğini ifade eder. Bilişsel çarpıtma olarak kavramsallaştırılan bu düşünme şekli, çoğunlukla hatalı işleyen, gerçek olup olmadığı yeteri kadar sınanmamış ve doğruluğuna ilişkin yeterli kanıt bulunmayan düşünceleridir (Childress ve Burns, 1981; Dobson, 2009; Dryden, David ve Ellis, 2009).

Çocuk ve ergenlerin gelişimsel sorunları onların sosyal, duygusal, fiziksel, bilişsel ve benlik özelliklerinden, önemli yaşam olaylarından ve sahip oldukları düşünme sisteminden etkilenir. Özellikle düşünce sistemleri aşırı talepkarlık, düşük engellenme eşiği, felaketleştirme, aşırı genelleme, kendini aşağılama gibi rasyonel olmayan özellikler gösterdiğinde ruhsal ve gelişimsel sorunların ortaya çıkma olasılığı oldukça artar (Vernon, 2002). Bireyin ruh sağlığını etkileme olasılığı yüksek olan bu rasyonel olmayan düşünme tarzının gözüktüğü alanlardan biri de akademik başarıya ilişkin beklenti ve inançlardır. Öğrenciler başarıya özellikle merkezi sınavlardaki başarıya bazen çok yüksek bir anlam yükleyebilmekte ve bu sınavlardaki başarı durumunu benlik değeri ile eş tutabilmektedirler. Bu aşırı anlam yükleme hali bazen çocuğun hiç hata yapmamak için kendini aşırı zorlamasına bazen de potansiyelinin altında bir performans sergilemesine neden olabilir (Özer, 1990). Bu çalışmada incelenen; ergenlerin katı ve yüksek başarı beklentileri, başarıya olduğundan daha büyük bir anlam yükleme, başarısızlığı bir felaket olarak değerlendirme ve başarı veya başarısızlığı kendi dışındaki etmenlere atfetme eğilimi Kaya (2018) tarafından akademik başarıya ilişkin bilişsel çarpitmalar olarak ifade edilmiştir.

BDT'ye göre bireyin ruh sağlığını etkileyen düşünce sisteminin oluşmasında aile, akran gibi içinde bulunulan sosyal süreçler oldukça önemlidir (Reinecke, Dattilio ve Freeman, 2015). Sigel ve Lisi (2002) ergenlerin rasyonel olmayan düşünme biçimlerinin kökeninin önemli oranda çocukluk dö- 
neminde anne baba tutum ve inançlarından kaynaklandığını ifade ederler. Bununla birlikte Dilmaç, Aydoğan, Koruklu ve Deniz (2009) yaptıkları çalışmada ergenlerin mantık dışı inançları ve mükemmeliyetçilik düzeyleri ile aile beklentileri ve ebeveyn eleştiri boyutları arasında pozitif yönlü ilişki olduğunu, Aydın (2018) ise ergenlerin başarı ve rahatlık ile ilgili bilişsel hatalarının anne baba davranışları ile ilişkili olduğunu belirlemiştir. Bununla birlikte anne babaların olumlu otomatik düşünceleri ile çocuklarının olumlu otomatik düşünceleri arasında anlamı ilişki olduğu (Donnelly et al., 2011) ve annelerin mükemmeliyetçi ve otoriter tutumları ile kız çocuklarının mükemmeliyetçilik düzeyleri ve psikopatolojik semptomları arasında ilişki olduğunu gösteren çalışmalar da mevcuttur (Frost, Lahart ve Rosenblate, 1991). Bilişsel davranışçı terapi temelli psiko eğitim programları ile anne babalara kazandırılan bazı becerilerin çocuklardaki davranış ve uyum sorunlarını azaltmada etkili olduğu (David, 2014; Karbasi Amel, Karbasi Amel ve Erfan, 2018) ve anne babaların rasyonel olmayan inanç ve streslerine yapılan müdahalelerin dolaylı olarak çocuklarının rasyonel olmayan düşüncelerini etkilediğini (Özcan ve Arslan, 2018) ortaya koyan çalışmalar da bulunmaktadır. Bu duruma ek olarak anne baba tutumlarının ergenlerin ruh sağlığı ile birlikte akademik yaşamlarını etkilediği de söylenebilir. Nitekim Toprakyaran (2016) yaptı̆̆ çalışmada anne baba tutumları ile lise öğrencilerinin akademik erteleme davranışları arasında anlamlı bir ilişki olduğunu, özellikle koruyucu ve otoriter tutum ile akademik erteleme davranışları arasında pozitif yönlü bir ilişki olduğunu ortaya koymuştur. Peker ve Kağızmanlı (2018) ise ergenlerin akademik güdülenmelerinin anne babalarından algıladığı kabul/ilgi düzeyleri pozitif ve denetleme düzeyi ile negatif yönlü ilişki gösterdiğini belirlenmişlerdir. Spera'nın (2005) yaptığı bir derleme çalışmasında ise anne baba davranışları ve anne babalık stilleri ile ergen akademik başarısı arasında ilişkili olduğu ortaya konmuştur.

Bilişsel, sosyal, fiziksel ve duygusal olarak hızlı değişimlerin yaşandığı ergenlik yıllarında gençler zamanlarının önemli bir kısmını okulda geçirmekte ve akademik çalışmalar birçok gencin hayatında önemli bir yer tutmaktadır. Türkiye'de orta öğretim (lise) akademik, mesleki/teknik ve din öğretimi olmak üzere üçe ayrılmakta ve Milli eğitim bakanlığı verilerine yaklaşık 5,6 milyon olan orta öğretim öğrencisinin üç milyondan fazlası ise akademik eğitim yapan okullara devam etmektedir (MEB, 2020). Bununla birlikte Türkiye'de eğitim kademeleri arasındaki geçişte akademik başarıyı 
ölçmek için ülke çapında uygulanan ve rekabete dayalı sınavların varlığ1 akademik başarının bazı öğrencilerin ve dolayısıyla da anne babalarının yaşamlarının merkezine yerleşmesine neden olmaktadır. Ergenlerde akademik başarı ile ruh sağlığı sorunları (Serin ve Topses, 2017; White, 2016) ve algılan akademik başarı ile psikolojik sağlamlık ve yaşam doyumu arasında anlamlı ilişkiler olduğu söylenebilir (Arıdağ ve Seydooğulları, 2018). Bunun yanında ergenlerin akademik başarıya yükledikleri anlam ve akademik yeterliliklerine ilişkin inançları onların akademik başarılarını etkileyebilmektedir (Caprara et al., 2011; Feldman ve Kubota, 2015; Koca ve Dadandı, 2019) Tüm bu çalışmalar göz önüne alındığında, ergenlerde akademik yaşam ile ruh sağllğı arasındaki ilişkinin arka planının ortaya konmasının alana katkı sağlayacağı söylenebilir.

Çocuk ve ergenlerde gelişimsel özelliklerinin ve rasyonel olmayan düşünüş tarzlarının anlaşılmasının, değerlendirme ve tedavi çalışmalarında oldukça önemli yer tuttuğu (Vernon, 2002) düşünüldüğünde ruh sağlığını etkileme potansiyeli bulunan akademik başarıya ilişkin bilişsel çarpıtmalar ile anne baba yaklaşımları ilişkisinin ortaya konması önleme ve tedavi çalışmalarına katkı sağlayabilir. Bu noktadan hareketle bu çalışmada ergenlerin anne babalarından algıladıkları tutumlar ile başarıya ilişkin bilişsel çarpıtmaları arasındaki ilişkilerin incelenmesi amaçlanmıştır.

\section{Yöntem}

\section{Çalışma Grubu}

Bu çalışma kapsamında; Gaziantep ili merkez ilçelerinde biri Anadolu, biri mesleki ve teknik eğitim olmak üzere iki farklı lisenin 246 öğrencisinde veri toplanmıştır. Verileri tarama temizleme çalışmaları kapsamında formları sistematik şekilde dolduran, maddelerin \%10'nundan fazlasını boş bırakan veya uç değer özelliği gösteren 26 kişinin verisi analiz dışı bırakılmış ve analizler 220 veri üzerinden gerçekleştirilmiştir. Çalışma grubuna ilişkin demografik özellikler incelendiğinde; katılımcllarının 15-19 yaş aralığında oldukları ( $\bar{x}=16,30 ;$ ss= .95) ve 79'unun kadın $(\% 35,9) 141$ 'inin erkek $(\% 64,1)$ olduğu belirlenmiştir. Grubun okul türü ve sinıf düzeyleri incelendiğinde 59'u 9. (\%26,8), 53'ü 10. (\%24,1), 84'ü 11. (\%38,2), 24'ü 12. (\%10,9) sinıfa devam ederken; 109'u $(\% 49,5)$ mesleki eğitim, 111'i $(50,5)$ akademik eğitim yapan liseye devam etmektedir. Öğrencilerin anne baba eğitim düzeyi ince- 
lendiğinde ise babaların \%38,6'sının ilkokul; \%32,3'sinin ortaokul; $\% 10,9$ 'unun lise, \%14,1'inin üniversite mezunu olduğu; annelerin $\% 43,6$ 'sının ilkokul, \%27,7'sinin ortaokul, \%11,4'ünün lise ve \%9,1'nin üniversite mezunu olduğu görülmüştür.

\section{Veri Toplama Araçları}

Anne baba tutum ölçeği (ABTÖ): Lamborn ve diğerleri (1991) tarafından geliştirilen ölçek, Yılmaz (2000) tarafından Türkçe 'ye adapte edilmiştir. 26 maddeden oluşan ölçme aracının kabul/ilgi, denetleme ve psikolojik özerklik olmak üzere üç alt boyutu bulunmaktadır. Aracın kabul/ilgi boyutu çocuğun anne babasından algıladığ nan kontrolü ve psikolojik özerklik boyutu ise çocuğun anne babasının kendisine tanıdığını düşündüğü bağımsızlığı/bireyselliği ölçmektedir. Aracın kabul/ilgi ve psikolojik özerklik boyutları 4'lü derecelendirme ile kontrol boyutunun maddelerinin bazıları üçlü derecelendirme bazıları ise bilgi alma sorularından oluşmaktadır. Ölçeğin Türkçe'ye adaptasyon çalışması ilköğretim, lise ve üniversitede eğitimine devam eden 920 kişi üzerinde yapılmıştır. Ölçeğin güvenirliği için üç farklı grup üzerinde yapılan test tekrar test ve cronbach alfa iç tutarlılık analizi ile incelenmiş yeterli güvenirlik değerlerine sahip olduğu belirlenmiştir. Geçerlik çalışması ölçüt geçerliği ve faktör analizi ile incelenmiş ve ilköğretim ve lise öğrencileri için üç faktörlü yapının doğrulandığı belirlenmiştir (Yılmaz, 2000). Ölçeğin bu çalışmada yapılan iç tutarlılık analizinde kabul/ilgi boyutu için .65; psikolojik özerklik için .72 ve kontrol boyutu için .61 Cronbach's Alfa değeri elde edilmiştir. Bu değerler, ölçeğin bu araştırmadaki güvenirliğinin yüksek olmasa da kabul edilebilir sinırlar içerisinde olduğunu göstermektedir (Özdamar, 1999).

Akademik başarnya ilişkin bilişsel çarpıtmalar ölçeği (АВїBÇÖ): Ergenlerin akademik başarıya ilişkin bilişsel çarpıtmalarını değerlendirmeyi amaçlayan ölçek Kaya (2018) tarafından 606 lise öğrencisi üzerinde geliştirilmiştir. Ölçeğin geliştirme sürecinde ilk olarak açımlayıcı faktör analizi yapılmış ve toplam varyasın \%50.87' sini açıklayan dört faktörlü bir yapı elde edilmiştir. Ardından bu yapının model uyumunu değerlendirme için doğrulayıcı faktör analizi yapılmış ve elde edilen verilerden dört faktörlü yapının doğrulandığ1 görülmüştür $\left(\mathrm{X}^{2} / \mathrm{sd}=2,29 ; \mathrm{RMSEA}=.08 ; \mathrm{NNFI}=.95 ; \mathrm{CFI}=.95\right.$; $\mathrm{SRMR}=.08)$. Güvenirlik çalışmaları kapsamında yapılan Cronbach's Alfa 
(.89), test tekrar test güvenirliği (.89) ve yapısal güvenirlik (.94) analizi sonuçları aracın yüksek güvenirlik değerlerine sahip olduğunu göstermiştir. Beşli likert tipi derecelendirme ile puanlanan aracon 25 maddesi ve felaketleştirme, benlik değeri, dışa atıf ve mükemmeliyetçilik olmak üzere dört alt boyutu bulunmaktadır. Alt boyutlardan felaketleştirme ergenlerin başarısızlığa aşırı anlam yükleyerek bunu bir felaket olarak değerlendirmesini, benlik değeri kişisel değerini başarı üzerinden tanımlamasını, dışa atıf başarı veya başarısızlığı başkalarına yüklemesini ve mükemmeliyetçilik ise başarıya dair katı ve yüksek standartlarını ölçmektedir. 25 ile 125 puan aralığında değerlere ulaşılabilen araçta yüksek puan bilişsel çarpıtma düzeyinin yüksekliğini göstermektedir (Kaya, 2018). Bu çalışma kapsamında yapilan güvenirlik analizinde ölçeğin felaketleştirme boyutu .87, benlik değeri .72, dişa atıf .65, mükemmeliyetçilik .83 ve ölçeğin toplamı .91 Cronbach's Alfa iç tutarlılık değerine sahip olduğu belirlenmiştir. Elde edilen bu değerler ölçeğin bu çalışmada yeterli güvenirlik düzeyine sahip olduğunu göstermektedir.

\section{Verilerin Toplanmast}

$\mathrm{Bu}$ çalışmanın verileri; Gaziantep üniversitesi sosyal ve beşeri bilimler etik kurulu komisyonundan (20.03.2020 tarih, 4 nolu toplantı, 07 nolu karar) ve milli eğitim bakanlığından alınan izin kapsamında toplanmıştır. Veriler, sosyo ekonomik olarak farklılıklar içerdiği belirlenen biri Anadolu biri meslek lisesinde yapılan uygulamalardan elde edilmiştir. Formlar uygulanmadan önce ilk olarak çalışma hakkında bilgi verilmiş ve öğrencilerden çalışmaya katılmayı isteyip istemediklerini işaretlemeleri istenerek, katılımın gönüllülüğü sağlanmıştır. Formların uygulanması yaklaşı 10-15 dakika kadar sürmüştür.

\section{Verilerin Analizi}

Verilerin analizine geçilmeden önce formlar taranmış, \% 10'dan fazla boş bırakma ve hatalı veya sistematik kodlamanın olduğu 18 form ile Mahalanobis değerlerinden hareketle uç değer gösteren 8 kişinin verisi analiz dış1 bırakılmıştır. Analizler yapılmadan önce veriler üzerine ne tür analizlerin yapılabileceğini belirlemek için temel varsayımlar test edilmiştir. Bu kapsamda normallik, doğrusallık ve eş varyanslılık ve sorunu olup olmadığı 
incelenmiş ve bu analizler sonucunda verilerin parametrik özellikler gösterdiği ve regresyon analizinin temel varsayımlarını karşıladığı tespit edilmiştir. Bu sonuçlardan hareketle analizlerde $t$ testi, ANOVA, korelasyon ve regresyon analizlerinin yapılmasına karar verilmiş ve analizler SPSS paket programı ile .05 anlamlılık düzeyinde yapılmıştır.

\section{Bulgular}

Araştırmanın temel analizlerine geçmeden önce değişkenlerin demografik özellikler göre incelenmesinin bulguları yorumlamaya katkı sağlayacağ1 düşünüldügünnden $\mathrm{ABIBBÇÖ} \mathrm{ve} \mathrm{anne} \mathrm{baba} \mathrm{tutumları} \mathrm{ölçeklerinin} \mathrm{puanları}$ cinsiyet ve okul türüne göre incelenmiştir.

Tablo 1. АВїВÇÖ ve Anne baba tutumlarnnı cinsiyet ve okul türü değişkenlere göre farklılaşma düzeyini gösterir $t$ testi sonuçlan

\begin{tabular}{|c|c|c|c|c|c|c|c|c|}
\hline Değişken & & & $\mathbf{n}$ & $\bar{x}$ & Ss & sd & $t$ & p \\
\hline \multirow{4}{*}{ АВїBÇÖ } & & Kadın & 79 & 54,16 & 16,31 & 218 & $-1,88$ & .06 \\
\hline & & Erkek & 141 & 58,39 & 15,91 & & & \\
\hline & & Anadolu & 111 & 55,33 & 15,82 & 218 & $-1,44$ & .15 \\
\hline & & Meslek & 109 & 58,44 & 16,40 & & & \\
\hline \multirow{12}{*}{$\begin{array}{l}\text { Anne baba } \\
\text { Tutumu }\end{array}$} & \multirow[t]{2}{*}{ Kabul/İlgi } & Kadın & 79 & 27,92 & 4,07 & 218 & 1,21 & .21 \\
\hline & & Erkek & 141 & 27,17 & 4,64 & & & \\
\hline & \multirow[t]{2}{*}{ Özerklik } & Kadın & 79 & 24,52 & 5,56 & 218 & 1,80 & .08 \\
\hline & & Erkek & 141 & 23,17 & 5,19 & & & \\
\hline & \multirow[t]{2}{*}{ Denetleme } & Kadın & 79 & 27,69 & 3,52 & 218 & 4,60 & $.00^{*}$ \\
\hline & & Erkek & 141 & 24,66 & 5,22 & & & \\
\hline & \multirow[t]{2}{*}{ Kabul/ligi } & Anadolu & 111 & 27,85 & 4,13 & 218 & 1,39 & .17 \\
\hline & & Meslek & 109 & 27,02 & 4,75 & & & \\
\hline & \multirow[t]{2}{*}{ Özerklik } & Anadolu & 111 & 25,09 & 5,68 & 218 & 4,17 & $00^{*}$ \\
\hline & & Meslek & 109 & 22,19 & 4,57 & & & \\
\hline & \multirow[t]{2}{*}{ Denetleme } & Anadolu & 111 & 26,30 & 4,33 & 218 & 1,69 & .09 \\
\hline & & Meslek & 109 & 25,19 & 5,37 & & & \\
\hline
\end{tabular}

$\mathrm{n}=220 \quad * \mathrm{p}<.01$

Yapılan bu analizlerde ABİBÇÖ'nün cinsiyet $(\mathrm{t}(218)=1,88 ; \mathrm{p}>$.05) ve okul türüne $(\mathrm{t}(218)=1,44 ; \mathrm{p}>.05)$ göre anlamlı bir farklılık göstermediği belirlenmiştir. Bunun yanında anne baba tutum ölçeği alt boyutlarından kabul/ilgi $\left(t_{(218)}=1,21 ; p>\right.$.05) ve psikolojik özerklik $\left(t_{(218)}=1,80 ; p>.05\right)$ cinsiyete göre farklılık göstermez iken denetlemenin kadınlar lehine anlamlı farklılık göstermektedir $(\mathrm{t}(218)=4,60 ; \mathrm{p}<.05)$. Okul türüne göre anne baba tutumlarının farklılaşma durumu incelendiğinde ise kabul/ilgi $(\mathrm{t}(218)=1,39 ; \mathrm{p}>.05)$ ve denetlemenin $(t(218)=1,69 ; \mathrm{p}>.05)$ okul türüne göre farklılık göstermediği, 
psikolojik özerkliğin ise Anadolu Lisesi lehine anlamlı farklılık gösterdiği ( $\mathrm{t}$ $(218)=4,17 ; \mathrm{p}<.05)$ belirlenmiştir.

Temel demografik analizin ardından değişkenler arasındaki ilişkileri ortaya koymak için Pearson korelasyon analizi yapılmış ve sonuçları tablo 2'de gösterilmiştir.

Tablo 2. Değişkenlerin aritmetik ortalama, standart sapma, basıklık/çarpıklık ve korelasyon değerleri

\begin{tabular}{lllll}
\hline Değişkenler & $\mathbf{1}$ & $\mathbf{2}$ & $\mathbf{3}$ & $\mathbf{4}$ \\
\hline 1.Kabul/ilgi & 1 & & & \\
\hline 2.Özerklik & $.15^{* *}$ & 1 & 1 & \\
\hline 3.Denetleme & $.20^{*}$ & -.07 & .12 & 1 \\
\hline 4. ABİBÇÖ & -.05 & $-.36^{*}$ & 25,75 & 56,87 \\
\hline$\overline{\mathbf{X}}$ & 27,43 & 23,65 & 4,90 & 16,15 \\
\hline Ss & 4,46 & 5,35 & -.76 & .12 \\
\hline Skewness/Basıklık & -.63 & -.11 & .12 & -.46 \\
\hline Kurtosis/Çarpıklık & .10 & -.44 & & \\
\hline
\end{tabular}

$\mathrm{n}=220 * \mathrm{p}<.01 ; * * \mathrm{p}<.05$

Tablo 2'de görüldüğü üzere ABİBÇÖ ile algılanan özerklik arasında negatif yönlü orta düzeyde anlamlı bir ilişki bulunurken $(r=-.36 ; \mathrm{p}<.01)$ ABİBÇÖ ile algilanan kabul/ilgi $(r=-.05 ; \mathrm{p}>.05)$ ve denetleme $(\mathrm{r}=.12 ; \mathrm{p}>.05)$ arasında anlamlı bir ilişki bulunmamaktadır.

Değişkenler arasındaki ilişki incelendikten sonra anlamlı ilişki gösteren değişkenler basit doğrusal regresyon analizine tabi tutulmuş ve sonuçlar tablo 3 'te sunulmuştur.

Tablo 3. Algılanan özerkliğin ABİBÇÖ toplam puanın yordamasına ilişskin basit doğrusal regresyon analizi

\begin{tabular}{|c|c|c|c|c|c|c|c|c|}
\hline Değişkenler & B & $\mathrm{SH}$ & $\beta$ & $\mathrm{T}$ & $\mathrm{F}$ & $\mathrm{R}$ & $\mathrm{R}^{2}$ & $\Delta R^{2}$ \\
\hline Sabit & 82,760 & 4,62 & & $17,92^{*}$ & 33,02 & .36 & .13 & .13 \\
\hline Özerklik & $-1,09$ & .19 & -.36 & $-5,75^{*}$ & & & & \\
\hline
\end{tabular}

Tablo 3 incelendiğinde ABİBÇÖ puanının anne babadan algılanan özerklik puanı tarafından anlamlı şekilde yordandığı belirlenmiştir.

$\left(\Delta \mathrm{R}^{2}=.13 ; \mathrm{F}_{\mathrm{Reg}}=33,02 ; \mathrm{p}<.01\right)$. Bu değerlerden hareketle özerklik puanlarının ABİBÇÖ puanında gözlenen varyansın \%13'ünü açıkladığı söylenebilir. 


\section{Tartışma ve Sonuç}

BDT'ye göre bireyin ruh sağlığı üzerinde önemli bir faktör olan düşünceler, işlevsel ve işlevsel olmayan özellikler taşıyabilir. Bireyin kendine, diğer insanlara ve dünyaya ilişkin uyumlu veya uyum bozucu etkileri olan inanç ve düşüncelerinin oluşmasında ve şekillenmesinde belirleyici kaynaklardan biri çocukluk ve ergenlik yıllarında anne baba ve diğer insanlarla girilen sosyal etkileşimlerdir (A. T. Beck ve Weishaar, 1989; J. S. Beck, 2006). Bu çalışmada akademik başarıya ilişkin bilişsel çarpıtmalar anne babadan alg1lanan kabul ve denetimden çok psikolojik özerklik ile ilişkili bulunmuştur. Bu bulgu ergenlerin başarıya ilişkin rasyonel olmayan düşünceleri üzerinde çocuğun seçimlerine ne kadar saygı duyulduğunun daha önemli olduğunu göstermektedir. Bu durum anne babaların çocuğun akademik yaşamına örneğin kendi bireysel çalışma alışkanlıkları geliştirmesine, ders, okul türü, etüt merkezi, hatta meslek gibi seçimlerine hangi düzeyde saygı duyduğunun, çocuğun başarıya yüklediği anlamı etkilediğini göstermektedir. Bunun yanında algılanan özerklik ile bilişsel çarpıtmalar arasında ortaya konan bu bulgu akademik temelli bilişsel çarpıtmaları müdahale ederken anne babaların çocukların seçim ve kararlarına yönelik yaklaşımlarının incelenmesi gerektiğini de göstermektedir.

Ergenlik dönemi ile beraber bireyin bağımsız hareket etme ve karar alma isteğinin belirginleştiği ve anne babalarından özerkleşerek kendine has bir kimlik geliştirme çabasının ön plana çıktı̆ı söylenebilir. Ergenlik döneminde özerklik duygusunun kazanması sağlıklı benlik gelişimi, kendini düzenleme, kendi davranışlarının sorumluluklarını alma ve sağlıklı kişiler arası ilişkiler geliştirme gibi birçok yaşamsal becerinin gelişmesine destek sağlar (Collins ve Laursen, 2004; Lerner ve Steinberg, 2004). Psikososyal gelişim kuramının öncüsü olan Ericson ergenlik yıllarını kimliğe karşı rol karmaşası krizi olarak tanımlar ve kimlik kazanımının önemli koşullarından birinin ergenin özerkleşmesi olduğunu ifade eder (Gander ve Gardiner, 2004; İnanç vd., 2007). Bu çalışmada ergenlerin akademik başarıya ilişkin bilişsel çarpıtmaları ile ilişkili bulunan anne babadan algılanan psikolojik özerklik, ergenin anne babadan algıladığı bağımsızlık duygusudur. Anne babadan algılanan özerklik arttıkça bilişsel çarpıtmaların azalması; bağımsız karar alması, kendi başına hareket etmesi desteklenen ve seçimlerine saygı duyulan çocukların başarıyı daha sağlıklı değerlendirdiği sonucuna götürebilir. 
Anne baba tutum, yaklaşım ve davranışlarının doğrudan ve dolaylı olarak çocuğun biliş, duygu ve davranışları üzerinde etkileri olabilir. Sümer, Gündoğdu ve Helvacı (2010) anne baba tutum ve davranışlarının etkilerini araştıran 34 yayını derledikleri meta analiz çalışmasında genel olarak baskı, disiplin ve aşırı koruyuculuğun çocuk ve ergenleri olumsuz, demokratik ve kabul edici tutumların olumlu etkilerinin olduğunu belirlemişlerdir. Erkman ve Rohner (2006) anne ve babadan algılanan kabulün ergenlerin psikolojik uyumunun anlamlı bir yordayıcısı olduğunu, Haktanır ve Baran (1998) ise ergenlerin anne babalarını demokratik olarak algıladığında benlik sayg1larının yükseldiğini, otoriter ve ilgisiz algıladığında ise düştügünü belirlemişlerdir. Bu çalışmada algılanan anne baba tutumlarından denetleme ve kabul/ilgi akademik başarıya ilişkin bilişsel çarpıtmalar ile ilişkili bulunmamıştır. Bu bulgu anne babaların otorite temelli kontrol davranışlarının ve çocuklarıyla hangi düzeyde ilgilendiklerinin çocuğun başarı ile ilgili inançları üzerinde etkili olmadığını göstermektedir. Bu bulgu değerlendirilirken akademik başarının, başarıya ilişkin inançlar ile ilişkili olmayabileceği göz önüne alınmalıdır. Nitekim АВİBÇÖ puanlarının akademik ve mesleki eğitim yapan okul türüne göre farklılaşmıyor olması iddiayı güçlendirmektedir.

Anne baba yaklaşımı çocuğun genel ruh sağlığı ve uyumunun yanında çocuğun akademik yaşamını da etkilediği söylenebilir. Yılmaz (2001) lise öğrencilerinin anne babadan algıladığı psikolojik özerklik puanı yükseldikçe akademik yeterliliklerinin, akademik başarılarının ve öz değerinin yükseldiğini belirlemiştir. Anne ve babalarından otoriter tutum algılayanların demokratik tutum algılayanlara göre daha yüksek öğrenilmiş çaresizlik yaşadığı (Erdoğdu, 2006) ve anne baba çocuk yetiştirme tarzının çocuğun öğrenilmiş yetkinliğini (Türkel ve Tezer, 2008) etkildiği söylenebilir. Ayrıca koruyucu ve otoriter tutum ile akademik erteleme davranışları arasında pozitif yönlü bir ilişki olduğu (Toprakyaran, 2016) ve akademik güdülenmenin anne babadan algilanan kabul/ilgi ve denetleme düzeyi ile ilişki gösterdiği (Peker ve Kağızmanll, 2018) bulgusu ergenlerin akademik dünyası ile anne baba yaklaşımları arasında doğrudan bir ilişki olduğunu göstermektedir. Araştırmalardan elde edilen bu sonuçlardan hareketle anne babaların çocuklar için koyduğu yüksek standartlar çocukların da içsel olarak yüksek standartlar belirlemesine ve bu standartlara ulaşamadığında duygusal bazı problemler yaşamasına neden olabileceği söylenebilir. Özellikle 
anne babaların çocuklardan yüksek başarı beklentileri veya başarıya yükledikleri anlam, çocukların başarı veya başarısızlığa olduğundan daha yüksek bir değer atfetmesine neden olabilir.

Bu çalışmada ergenlerin akademik başarıya ilişkin bilişsel çarpıtmalarının farklı başarı düzeyine sahip okul türüne göre farklılaşmadığı belirlenmiştir. Bu bulguya benzer şekilde Tekgül (2015) ergenlerin kaygı, bilişsel hataları ve akademik başarılarına yönelik hazırladığı psikoeğitim programının kaygı ve bilişsel çarpıtmalar üzerinde etkili olduğunu ancak akademik başarıya etki etmediğini belirlemiştir. Bu noktada bilişsel hatalar değişse de başarının hemen değişmeyebileceği söylenebilir. Yine benzer şekilde Aydın (2018) ergen mantık dışı inançlarının algılanan akademik başarıya göre farklılaşmadığını tespit etmiştir. Yüksek ve düşük akademik başarı gösteren öğrenciler arasında ABİBÇÖ puanının farklılaşmaması akademik başarıya her iki grupta da benzer bir anlam yüklendiğini ve yüklenen anlamın bilişsel fonksiyonlardan çok öğrencinin duygusal özelliklerini etkilediği şekilde yorumlanabilir. Çalışmadan elde edilen bir diğer sonuç ABİBÇÖ puanlarının cinsiyete göre farklılaşmamasıdır. Bu bulguya benzer şekilde üniversite öğrencilerinde ilişkilere ilişkin bilişsel çarpıtmaların (Çelikkaleli ve Kaya, 2016) ergenlerde akılcı olmayan inançların yoğunluğunun (Karaman, 2018) cinsiyete göre farklılaşmadığını gösteren çalışmalar mevcuttur. Bu durum akademik yaşama yüklenen anlamin ve rasyonel olmayan beklentilerin cinsiyet değişkeninden etkilenmediğini her iki cinsiyetin de benzer bilişsel içeriklere sahip olduğunu göstermektedir.

Çalışmada ayrıca algılanan anne baba tutumlarından özerkliğin Anadolu lisesi lehine farklılaştığı görülmüştür. Anadolu liselerinin meslek liselerinden daha yüksek akademik başarı gösteriyor olması, burada okuyan öğrencilere tanınan özerkliğin yükselmesini veya yüksek özerklik tanındığ 1 için bu öğrencilerin daha yüksek akademik başarı elde etmiş olmasını sağlamış olabilir. Araştırmanın diğer bir bulgusu algılanan anne baba tutumlarından sadece denetlemenin kadınlar lehine anlamlı şekilde yüksek çıkmasidır. Bu durum toplumsal cinsiyet rolleri ile ilgili olabilir.

Anne baba tutumları ile ergenlerin akademik başarıya ilişkin bilişsel çarpıtmaların inceleyen bu çalışmada çocuğun annesinden ve babasından algıladığı yaklaşımın her zaman uyum göstermeyebileceği gerçekliğine rağmen anne baba tutumlarını değerlendiren ABTÖ'nün tutumu bir bütün değerlendirmesinin bir sınırlılık olduğu düşünülmektedir. Bunun yanında 
anne baba yaklaşımları ile akademik başarıya ilişkin bilişsel çarpıtmaları birlikte inceleyecek araştırmacıların anne baba tutumunu çocuğun algısının yanında doğrudan anne babadan alınan bilgiler çerçevesinde değerlendirmesinin alana katkı sağlayabilir.

\section{Etik Bildirim}

Bu çalışma, Gaziantep üniversitesi sosyal ve beşeri bilimler etik kurulu komisyonundan alınan izin (20.03.2020 tarih, 4 nolu toplantı, 07 nolu karar) çerçevesinde yapılmıştır. 


\title{
EXTENDED ABSTRACT
}

\section{The Relationship Between Cognitive Distortions Related to Academic Achievement and Perceived Parental Attitude at Adolescents}

\author{
İdris Kaya \\ Gaziantep University
}

Cognitive behavioural therapy (CBT) states that thoughts and beliefs are one of the main determinant of mental health and distorted cognitions in thinking system may be negatively affect mental health (Childress ve Burns, 1981; Dobson, 2009, p. 13; Dryden, David ve Ellis, 2009). When the thought systems of children and adolescents show non-rational characteristics such as demanding, low frustration tolerance, awfulizing, overgeneralization and self-downing the probability of developing mental and developmental problems increases considerably (Vernon, 2002, p. 12-14). One of the areas where the individual's dysfunctional thinking style appears is the expectations about academic achievement. Students sometimes attribute a very high meaning to success, especially in central exams, and they can match the success of these exams with their self-worth. This excessive meaning sometimes causes the child to push himself too hard to make no mistakes, and sometimes to perform under his/her potential (Özer, 1990). According to the Ministry Education of Turkey data, there are approximately 5.6 million high school students and more than three million of them attend academic schools (MEB, 2020). These ratios indicate that for adolescents living in Turkey is very important to be academically successful. The existence of competitive exams applied across the country to measure academic success, especially in the transition between educational levels, causes academic success to be at the centre of the lives of some students and, therefore, their parents. Based on the assumption that social processes such as family and peer are very important in shaping the thought system that affects the mental health of the individual (Reinecke, Dattilio ve Freeman, 2015, p. 40-41) in this study, it was aimed to investigate the relationships between the parents' 
attitude and the adolescent cognitive distortions related to academic achievement.

The data of the study were collected from two high schools which one academic and one vocational. Working group consists of a total of 220 high school students between the ages of $15-19(\bar{x}=16.30$; ss $=.95)$ and 79 of them are female (35.9\%) and 141 of them are male (64.1\%). When the school type and class levels of the group were examined; 59 (26.8\%) of them are 9., 53 (24.1\%) of them are $10 ., 84(38.2 \%)$ of them are $11 ., 24(10.9 \%)$ of them are 12 class and 109 (49.5\%) attend vocational high school, while 111 (50.5) attend academic high school. The data of the study were collected by the parental attitude scale (PAS) adapted by Yilmaz (2001) and the cognitive distortions scale related to academic achievement (CDS-AA) developed by Kaya (2018).

The findings of the study show that cognitive distortions related to academic achievement do not differ significantly by gender and school type. Acceptance / involvement and psychological autonomy from parents' attitudes not differ by gender, whereas the strictness/supervision differs significantly in favour of women. However, while acceptance / involvement and strictness/supervision did not differ according to the school type, psychological autonomy showed a significant difference in favour of academic high school. When the relationship between the variables was analysed, it was determined that there was a moderate negative relationship between CDSAA and psychological autonomy, and there was no significant relationship between CDS-AA and acceptance / involvement and strictness/supervision. In the regression analysis conducted between the variables, it was seen that the perceived psychological autonomy explained CDS-AA's 13\% of the variance.

Findings obtained from this study support the assumption that one of the factors affecting the dysfunctional thinking styles of adolescents is parents' attitudes and beliefs (Sigel and Lisi, 2002). In the study, cognitive distortions related to academic success were associated with psychological autonomy rather than perceived acceptance and control from parents. It can be stated that as the autonomy perceived by adolescents from parents increases, their cognitive distortions decrease. This result shown when parents' support to children to act independently, the ability to move on its own and respect the child's choices, It can be contributes to keep the meaning of the successful as functional and more rational evaluation of exam and suc- 
cess by adolescents. It can be said that especially with the adolescence period, the individual's desire to act independently and to make own decisions becomes prominent and the effort to develop a identity by becoming autonomous from their parents comes to the fore. Gaining a sense of autonomy during adolescence supports the development of many vital skills such as healthy self-development, self-regulation, taking responsibility for their own behaviour and developing healthy interpersonal relationships (Collins and Laursen, 2004; Lerner and Steinberg, 2004). This finding, which is revealed between perceived autonomy and cognitive distortions, suggests that when intervention to academic based cognitive distortions, parents' approaches to children's decisions should be examined.

\section{Kaynakça / References}

Arıdağ, N. Ç., ve Seydooğulları, S. Ü. (2018). Lise öğrencilerinin yaşam doyumu ve yllmazlık düzeylerinin anne-baba tutumlarıyla ilişkisi açısından incelenmesi. Hacettepe Üniversitesi Ë̆itim Fakültesi Dergisi, 34(4), 1037-1060.

Aydın, F. (2018). Ergenlerde mantıkdışı inançları anne baba dauranışlarıyla ilişkisinin incelenmesi. Yayımlanmamış yüksek lisans tezi. Ankara Üniversitesi.

Barrett, P. M., Duffy, A. L., Dadds, M. R., ve Rapee, R. M. (2001). Cognitive-behavioral treatment of anxiety disorders in children: Long-term (6-year) follow-up. Journal of Consulting and Clinical

Beck, A. T., ve Weishaar, M. (1989). Cognitive Therapy. Comprehensive Handbook of Cognitive Therapy içinde (s. 21-36). Springer, Boston, MA. https://doi.org/10.1007/978-1-4757-9779-4_2

Beck, J. S. (2006). Bilişsel davramış̧ terapi: Temelleri ve ötesi. Nobel Akademik Yayıncllk.

Caprara, G. V., Vecchione, M., Alessandri, G., Gerbino, M., ve Barbaranelli, C. (2011). The contribution of personality traits and selfefficacy beliefs to academic achievement: A longitudinal study. British Journal of Educational Psychology, 81(1), 78-96. https://doi.org/10.1348/2044-8279.002004

Childress, A. R., ve Burns, D. D. (1981). The basics of cognitive therapy. Psychosomatics, 22(12), 1017-1020.

Collins, W. A., ve Laursen, B. (2004). Parent-adolescent relationships and influences. R. M. Lerner ve L. Steinberg (Eds.), Handbook of adolescent psychology içinde (Cilt 2, s. 331-362). 
Çelikkaleli, Ö., ve Kaya, S. (2016). University Students' Interpersonal Cognitive Distortions, Psychological Resilience, and Emotional Self-Efficacy According to Sex and Gender Roles.Pegem Journal of Education and Instruction; Ankara, 6(2), 187212. http://dx.doi.org/10.14527/pegegog.2016.011

David, O. A. (2014). The rational positive parenting program for child externalizing behavior: Mechanisms of change analysis. Journal of Evidence-Based Psychotherapies, 14(1), 21.

Dilmaç, B., Aydoğan, D., Koruklu, N., ve Deniz, M. E. (2009). İköğretim öğrencilerinin mükemmeliyetçilik özelliklerinin mantıkdışı inançlarla açıklanabilirliği. Ilköŏgretim Online, 8(3), 720-728.

Dobson, K. S. (2010). Handbook of cognitive-behavioral therapies, Third Edition. Guilford Press.

Donnelly, R., Renk, K., Sims, V. K., ve McGuire, J. (2011). The relationship between parents' and children's automatic thoughts in a college student sample. Child Psychiatry \& Human Development, 42(2), 197-218.

Dryden, D., David, D., ve Ellis, A. (2009). Rational emotive behavior therapy. In K. S. Dobson (Ed.), Handbook of cognitive-behavioral therapies içinde (s. 226-276). Guilford Press.

Erdoğdu, M. Y. (2006). Ana-baba tutumları ile öğretmen davranışlarının çocuklarda öğrenilmiş çaresizlik düzeyi ile ilişkileri. Çocuk ve Gençlik Ruh Sağhl̆ğ Dergisi, 13(3), 98-105.

Erkman, F., ve Rohner, R. P. (2006). Youths' perceptions of corporal punishment, parental acceptance, and psychological adjustment in a Turkish metropolis. Cross-Cultural Research, 40(3), 250-267.

Feldman, D. B., ve Kubota, M. (2015). Hope, self-efficacy, optimism, and academic achievement: Distinguishing constructs and levels of specificity in predicting college grade-point average. Learning and Individual Differences, 37, 210-216. https://doi.org/10.1016/j.lindif.2014.11.022

Frost, R. O., Lahart, C. M., ve Rosenblate, R. (1991). The development of perfectionism: A study of daughters and their parents. Cognitive Therapy and Research, 15(6), 469-489. https://doi.org/10.1007/BF01175730

Gander, M. J., ve Gardiner, H. W. (2004). Çocuk ve ergen gelisimi (B. Onur, Trans.). İmge kitapevi.

Haktanır, G., ve Baran, G. (1998). Gençlerin benlik saygısı düzeyleri ile anne baba tutumların algilamalarının incelenmesi. Çocuk ve Gençlik Ruh Sağlı̆̆ı Dergisi, 5(3), 134-141. 
İnanç, B. Y., Bilgin, M., ve Atıc, M. K. (2007). Gelişim psikolojisi (3. Baskı). Pegem Akademi.

Karbasi Amel, A., Karbasi Amel, S., ve Erfan, A. (2018). Effectiveness of parentsfocused cognitive-behavioral therapy on attention deficit hyperactivity disorder symptoms, obesity and self-esteem of overweight children with attention deficient hyperactivity disorder. Advanced Biomedical Research, 7. https://doi.org/10.4103/abr.abr_170_17

Karaman, H. (2018). 15-18 yaş ergenlerde akilci olmayan inançlar ve psikolojik belirtiler. Yayımlanmamış yüksek lisans tezi, Nişantaşı Universitesi, Istanbul.

Kaya, İ. (2018). Akademik başarıya ilişkin bilişsel çarpıtmalar ölçeğinin (ABIBÇÖ) geliştirilmesi. Mersin Üniversitesi Eğitim Fakültesi Dergisi, 1082-1098. https://doi.org/10.17860/mersinefd.435605

Kazantzis, N., Luong, H. K., Usatoff, A. S., Impala, T., Yew, R. Y., ve Hofmann, S. G. (2018). The processes of cognitive behavioral therapy: A review of metaanalyses. Cognitive Therapy and Research, 42(4), 349-357. https://doi.org/10.1007/s10608-018-9920-y

Koca, F., ve Dadandı, I. (2019). Akademik öz-yeterlik ile akademik başarı arasındaki ilişkide sınav kaygısı ve akademik motivasyonun aracı rolü. Elementary Education Online, 18(1).

Lerner, R., ve Steinberg, L. (2004). Handbook of adolescent psychology: Vol. Second Edition. New York: Wiley.

McGuire, J. F., Piacentini, J., Lewin, A. B., Brennan, E. A., Murphy, T. K., ve Storch, E. A. (2015). A meta-analysis of cognitive behavior therapy and medication for child obsessive-compulsive disorder: Moderators of treatment efficacy, response, and remission. Depression and Anxiety, 32(8), 580-593. https://doi.org/10.1002/da.22389

MEB. (2020). Millî Eğitim istatistikleri örgün eğitim 2019-2020. http://sgb.meb.gov.tr/www/icerik_goruntule.php?KNO=396

Özcan, N. A., ve Arslan, R. (2018). Ergen annelerine uygulanan ebeveyn stresini yönetme programı'nın etkililiği. Sakarya University Journal of Education, 8(2), 4059.

Özdamar, K. (1999). Paket programlar ile istatiksel veri analizi: SPSS-MINITAB. Kaan Kitabevi.

Özer, A. K. (1990). Sinav ve stnanma kaygısı. Varlık Yayınları.

Peker, A., ve Kağızmanl, N. (2018). Ebeveyn tutumlarının ergenlerin akademik güdülenme düzeyleri üzerindeki yordayıcı etkisi. Mersin Üniversitesi Ĕ̆itim Fakültesi Dergisi, 14(1), 210-224. 
Reinecke, M. A., Dattilio, F. M., ve Freeman, A. (2015). Etkili bir tedaviyi oluşturan unsurlar nelerdir? M. A. Reinecke, F. M. Dattilio, ve A. Freeman (Eds.), \& Y. S. Altındal (Trans.), Çocuk ve ergenlerde bilişsel terapi (s. 37-61). Litera Yayıncuk.

Rohde, P., Brière, F. N., ve Stice, E. (2018). Major depression prevention effects for a cognitive-behavioral adolescent indicated prevention group intervention across four trials. Behaviour Research and Therapy, 100, 1-6. https://doi.org/10.1016/j.brat.2017.10.013

Seligman, L. D., ve Ollendick, T. H. (2011). Cognitive-behavioral therapy for anxiety disorders in youth. Child and Adolescent Psychiatric Clinics of North America, 20(2), 217-238. https://doi.org/10.1016/j.chc.2011.01.003

Serin, N. B., ve Topses, G. (2017). Lise öğrencilerinde görülen psikolojik belirtilerin cinsiyet ve akademik başarı açısından incelenmesi. Electronic Turkish Studies, 12(18).

Sigel, I. E., ve Lisi, A. V. M. (2002). Parent beliefs are cognitions: The dynamic belief systems model. M. H. Borstein (Ed.), Handbook of parenting (2. Edition, Cilt 5, s. 485-508). Lawrence Erlbaum Associates.

Spera, C. (2005). A review of the relationship among parenting practices, parenting styles, and adolescent school achievement. Educational psychology review, 17(2), 125-146.

Sümer, N., Gündoğdu, E., ve Helvacı, E. (2010). Anne-Baba tutum ve davranışlarının psikolojik etkileri: Türkiye'de yapılan çalışmalara toplu bakış. Türk Psikoloji Yazulan, 13(25), 42-59.

Tekgül, N. (2015). Ergenlik döneminde bilişsel odakh psikoeğitim programının kaygı düzeyi, akademik başarı ve bilişsel hatalar ile etkileşiminin incelenmesi. Yüksek lisans tezi. Maltepe Üniversitesi,.

Toprakyaran, S. (2016). Lise son sinffögrencilerinin anne baba tutumlarn ile akademik erteleme davranışlan arasındaki ilişkinin incelenmesi. Yüksek lisans tezi. Haliç Üniversitesi.

Türkel, Y. D., ve Tezer, E. (2008). Parenting styles and learned resourcefulness of Turkish adolescents. Adolescence, 43(169).

Vernon, A. (2002). What works when with children and adolescents: A handbook of individual counseling techniques. Research Press.

White, G. W. (2016). Mental health and academic achievement: The effect of self-efficacy [Rutgers University - Graduate School - New Brunswick]. https://doi.org/10.7282/T3JH3PGX

Yılmaz, A. (2000). Anne-baba tutum ölçeğinin güvenirlik ve geçerlik çalışması. Çocuk ve Gençlik Ruh Sağlığı Dergisi, 7(3), 160-172. 
Yılmaz, A. (2001). Çocukların algıladığı anne baba arasındaki uyum, anne baba tutumu ve benlik algısı arasındaki ilişkiler. Çocuk ve Gençlik Ruh Să̆lğ̆ı Dergisi, 8(2), 85-93.

\section{Kaynakça Bilgisi / Citation Information}

Kaya, İ. (2020). Ergenlerde akademik başarıya ilişkin bilişsel çarpıtmalar ile algilanan anne baba tutumu arasındaki ilişki. OPUSUluslararası Toplum Araştırmaları Dergisi, 16(Eğitim ve Toplum Özel say1s1), 5565-5584. DOI: 10.26466/opus.791965 